\title{
Referencia Sobre la Obra de Santiago Argüello
}

$\mathbf{L}^{\wedge}$

A obra de Santiago Argüello o, mejor dicho, el conocimiento de su obra, arranca de los principios del siglo. Se significa entonces, en los primeros vagidos, por un tinte, por un colorido fuerte, de Trópico, de calentura. No hay un ciudadano consciente de estas latitudes de fragor que no haya entrado al horno de la política, que es politiquería criolla. $Y$ esa pasión influye en Santiago Argüello como ha influído en todos los escritores y poetas de Nicaragua, como influyó apasionadamente en el propio Rubén Darío en unas décimas partidaristas de que luego, en la madurez de la edad y dentro de la madurez de otros países atemperados, él mismo debe haberse sonreído piadosamente.

En los primeros años del siglo actual, se hacía política con el rifle y con el verso. Santiago Argüello escogió el camino más limpio físicamente: el del periódico, el del libro, el de la tribuna. Fué autor de proclamas y manifiestos; intervino en panfletos; pero siempre manteniendo el decoro de su túnica para no incurrir en las tristes contingencias del caudillo. Fué, más bien, maestro. La política es. necesaria; es ciencia de gobernar, como creo que han dicho otros. El disfraz que de ella se ha hecho en muchos países de América, resulta otra cosa. Por eso hay que calificar esa "otra cosa" como "politiquería".

Quemado por la candente política, transmite Santiago Argüello a sus versos el fuego de esa pasión, sobre todo en los primeros trabajos de prosa y verso. En este hombre de letras nicaragüense puede manifestarse bien marcado, como en pocos de nuestros ejemplares. americanos, el fuego de aquellas convicciones como derivación de: 
los fuertes colores tropicales. Poeta de colorido, el paisaje se vuelca en su interior receptivo y, elaborado ya, to devuelve sin perder sus aspectos esenciales: llanura ilímite, pero llanura feraz, tan distinta de la de los desiertos con que la Naturaleza no quiso fustigarnos; crepúsculos incendiados; selva acogedora y a la vez mortal con sus jugos salvajes y su sombra que no cobija sino que emborracha; lagos como mares de agua dulce en donde se revuelcan los tiburones de las extensiones salobres; volcanes; terremotos. Esta ígnea influencia se acentúa en la primavera literaria de Santiago Argüello y lo acompaña, desvanecida por el cultivo pero no desaparecida por completo, en los años posteriores, hasta cuando daba sus enseñanzas en la cátedra nacional o extranjera.

Del mismo modo, el poder romántico se transforma, se ordena en él con el tiempo. No deja de ser romántico nunca: se advierte en su estilo y en su vida, hasta en la obra filosófica que debería ser escueta, de aristas recias con filo. Se cuidó siempre de la forma, con una preocupación que arrebató mucho a la espontaneidad, a lo natural; pero en la última etapa de su labor ya no resalta el afán de arabesco, puede decirse que hasta churrigueresco, que salpica muchas de sus concepciones. La edad, otra vez el medio, la serenidad, entraban en los cauces tranquilos, aunque sin descuidar el estilo que, así, aparecía casi como natural en él con la metáfora rebuscada.

Esto, en términos generales y a vuelo de pájaro, sobre su copiosa obra.

Santiago Argüello lo comprendió todo, en el ramo de la literatura: poeta romántico en la recrudescencia del romanticismo de su tiempo; poeta modernista luego, hasta merecer el cognomento de "decadente" con que muchos ignorantes motejaban hasta al hoy "clásico" Rubén Darío; poeta épico, poeta filosófico si se admite el adjetivo o los dos adjetivos, ya que lo de poeta puede renunciar a su substantividad; dramático teatral en un ensayo bastante alejado de las realidades y hasta posibilidades de la escena, sin ser por eso ni cerebral ni pirandeliano. Creo que sólo en los caminos de la novela en sí no anduvo. Pero recorrió los del cuento, los del apólogo, los de la anécdota. Maestro, al final.

En 1903 publica Primeras ráfagas. No fué sino hasta diez años después cuando leímos, "sabiendo" leer ya, aquella explosión sentimental y caliente, enfrenada por las reglas de la Retórica. Exuberancia en todo, principalmente en la transcripción del paisaje tamizado por 
la cultura de un enciclopedista que admiraba a Rousseau al mismo tiempo que a Hugo y a Zola. La escuela francesa dominó en todo tiempo a Santiago Argüello, con sus conexiones hacia lo griego en arte y en filosofía. Francia, después, ya con canas, lo agitó con su humanismo, con su Revolución, con sus heroísmos, sus dolores y sus traspiés. Primeras ráfagas trae mucho local, regional, sin apegarse al costumbrismo.

Publica después Ritmo e idea, entrando ya con más certeza en la república del pensamiento, propiamente hablando. Puede seguirse la trayectoria del poeta con sólo analizar la intención de los títulos de sus libros. Aqui, el ritmo es capital. El ritmo desveló a Santiago Argüello, hasta hacerlo artífice en prosa, sin la soltura de los profesores o combatientes de hoy, en periodismo bien entendido sobre todo. (Santiago Argüzello fué periodista ; pero lo absorbió la lírica en los tiempos en que el periodismo comenzaba a ser tajante, como todas las escuelas de la verdad en lucha.)

Sigue a su edición de Ritmo e idea el libro que en los primeros tres lustros ejerció preponderancia en los sectores literarios de su patria y en algunas otras más: De tierra cálida. En él responde voluntariamente al imperativo del medio, del ambiente, del clima. La escena, lo natural y siempre el paisaje, tienen aquí muestrarios maestros. Pasa el costumbrismo bien seleccionado, aunque Argüello no haya sido costumbrista. Casi siempre, después de pensar en los costumbristas españoles de su tiempo - Palacio Valdés, Vicente Medina, Gabriel y Galán, etcétera-, él recorría los caminos de Francia con reminiscencias helenas. Dentro de ese tomo de Tierra cálida, "El vaquero del cortijo", bella poesía, revela la ubre, con todo y que el poeta quiso ser nativo y que nativa es la escena que describe. Pero no pudo ser sinceramente regional; el peso extraño, la influencia de los regionalismos extraños, gravitaba sobre su mente. $\mathrm{Y}$ así vemos cómo el protagonista de su poema es muy nuestro por la pasión, por el color y el calor de lo nuestro; pero bajo la "cotona" de manta se adivinan otras prendas que no usan nuestros labriegos. $\mathrm{Y}$ examinamos esa palabra tan castizamente española de "cortijo", "que no se usa por acá para señalar nuestras "haciendas", nuestros "potreros", nuestras "fincas", nuestras "huertas" que no son tampoco como las valencianas de España.

Continuamos examinando lo más cronológicamente posible, dentro del desorden bibliográfico nacional, la obra de Santiago Argüello. 
Publica después de Tierra cálida un interesante tomo modernista -modernista en proporción a la época-: El poema de la locura. Tanto de éste como del que le siguiera, Viaje al país de la decadencia, la masa académica y pesada, o la incomprensión rígida que no aceptaba simbolismos, dijo que eran libros incomprensibles. Es el mismo fenómeno que ya he citado atrás y que se refiere al "decadentismo" de Rubén Darío, quien va perdiendo ya su novedad aunque nunca su intensidad, frente a las corrientes nuevas de los abanderados revolucionarios del vanguardismo, que no cometen todavia el desacato o la vanidad de desconocer la inmensa obra de Rubén.

Lecciones de la Literatura Española vienen a sorprender a los maestros de entonces, que estaban acostumbrados a medir con centímetros los versos de los que no son poetas. Ese libro - decíanno era de lecciones de literatura. Eso constituía un disparate. $\mathrm{Y}$ no lo utilizaban ni para consulta los reaccionarios profesores de Literatura Española. La pléyade de figuras hispánicas que recorrian las páginas del libro estaba tratada con estilo sonoro, elevado, que no podrían comprender los alumnos de la clase. Esa especie de antología, de crítica, de exaltación, no era para medirse con el centímetro.

El sueño de Temistocles responde, como lo hemos dicho ya, al efecto del mirador exótico del poeta nicaragüense que, antena muy sensible, percibe las tonalidades de la historia de otros países y de otras edades.

Llega la primera guerra europea (esta segunda ya no sólo se circunscribe a Europa) y halla a Santiago Argüello en su puesto francófilo. La Revolución Francesa es la madre intelectual de los políticos, y de la ciudadanía en general, de los paises hispanoamericanos. En muchos conceptos, aquel movimiento engendró la independencia de varias de las repúblicas del nuevo continente. Con razón los gobernadores españoles de la colonia prohibían la publicación de noticias, verbales como se difundían las nuevas en aquélla época, y ocultaban los sacudimientos humanos que podían prolongarse en sacudimiento de las colonias. En Centroamérica, al menos, no seconocieron los de Francia sino cuando El Corso había penetrado en España. Entonces sí se publicaban los detalles de la injusticia francesa contra el derecho del pueblo español a la independencia, sin sospechar que el alegato de las autoridades españolas en América se revolvía contra la usurpación de parte de las mismas en el derecho americano. Argüello publica un hermoso poema: "Canto la Misión 
Divina de la Francia". Y casi a continuación, una serie de poemas patrióticos y contemporáneos de la vida contemporánea de Nicaragua bajo la intervención de la malhadada y por ventura ya muerta "política del dólar". (Para nosotros, Roosevelt es el revolucionario continental, caudillo sin sangre, a quien debemos $-\mathrm{y}$ ¿ por qué no deben también los Estados Unidos?- esa comprensión sincera y grande de la política del Buen Vecino.) Nuestro poeta se bate en dísticos y alejandrinos contra la injusticia de la intervención armada y fustiga la genuflexión de los almonedistas criollos.

Continúa en su trabajo político con La Guerra Europea ante la América Latina, que, como es de suponer, aborda los problemas que se deducen de aquella catástrofe, en relación con los países de este lado del Atlántico. Mucho de profecía tiene esta observación del compatriota.

Imprime después un poema sonoro: "La pena de muerte". Participa Santiago Argüello del generalizado sentimiento lírico en una naturaleza humana evolucionada, para censurar la pena de muerte. Mucho de Víctor Hugo sobre el mismo tema tiene esa concepción del poeta nicaragiuense, que no deja de hacer poesía y de sentir como poeta en un asunto que las legislaciones modernas han analizado perfectamente, dejando ir su fallo quirúrgico, hasta en el terreno previsor de la eugenesia. Países civilizados, con medios de toda clase para enmendar la criminalidad, con cárceles modelos, con laboratorios aplicados al hombre y con capacidad para estudiar no sólo los gérmenes sino las fuerzas psíquicas y de la herencia, han establecido la pena de muerte como medida radical de higiene. Y Santiago Argüello era abogado. Pero se imponía su estructura espiritual y sentimental sobre los códigos.

En seguida torna a la política continental y publica un ensayo sobre "La América Sajona ante la América Española", terminando un período, un ciclo que señala una honda diferencia en su labor y que deja lo poético en el pasado para comenzar el estudio filosófico y magisterial, psicológico y social. Empeño, este último, en donde le sorprende la muerte. La iniciación en la nueva forma la marcan las páginas de Letras apostólicas.

Peregrina ahora, en 1920, más o menos, ya no con la casaca diplomática que le presta oportunidades en Europa o América, ni con las facilidades económicas propias - pues la familia Argüello es de las más distinguidas en el país, con recursos materiales para saberse 
distinguir con buen gusto-, sino que va empujado por las circunstancias de declive monetario y por la obligación migratoria que imprimen los gobiernos reaccionarios de Nicaragua a los que no están de acuerdo con el sistema medioeval filosófico, que es al mismo tiempo sumisión ante los poderes extraños, espirituales y materiales.

Santiago Argüello emigra, como emigraron muchos, como tuvo que salir de su patria el que estas líneas escribe. $\mathrm{El}$ poeta lo hacía ya cansado, a los cincuenta años, con declinamientos corporales que cuentan mucho en los hiperestésicos. Va por Cuba, por los Estados Unidos, por Guatemala, por Honduras. En Guatemala, durante una de tantas residencias, logra amistad del general Ubico, progresista gobernante que, ante la noticia de que el profesor Argüello trata de salir de nuevo, con el objeto de buscar editor para sus libros, ordena la edición de ellos en la Imprenta Nacional. Son tomos de lujo, mecénicos, con amplia difusión. De las prensas oficiales guatemaltecas salen Mi mensaje a la juventud y otras orientaciones, El Divino Platón (dos tomos), El Libro de los Apólogos, La magia de Leonardo da Vinci, Poesias escogidas y poesías nuevas, Modernismo y modernistas.

$Y$ hubiera seguido la difusión; pero la inquietud muerde los calcañales del poeta, que torna a Cuba, de donde vuelve a Nicaragua con ese sino materializado en el caso de su predecesor Rubén Darío: sólo a morir a su patria.

Aquí, el gobierno del Presidente Somoza, ante una insinuación de los intelectuales de Cuba a la cabeza de los cuales figura Pastor del Río, no sólo le ofrece puesto público decoroso, sino que le brinda la oporttunidad de dirigir a la juventud nicaragüense desde el sitial del Ministerio de Instrucción Pública. Llega Santiago Argüello entre el anhelo de más sólida esperanza revolucionaria que ha abrigado la juventud, la intelectualidad de Nicaragua. $Y$ muere repentinamente, a los pocos días de su arribo, cuando ni siquiera había esbozado los profundos planes para la obra de regeneración.

Como Rubén Darío, vuelve a su suelo, a reposar definitivamente en él, en una fosa que recibe ofrendas de rosas deshojadas y lamentos.

Santiago Argüello ha dejado, además de la citada, una colección muy importante de trabajos inéditos. Ya me he referido a la preocupación de sus últimos años, como maestro. Un libro que conserva la familia lleva el título de La educación del porvenir. Son dos tomos 
cuyos capítulos no renuncio a enumerar, para mejor comprensión de su objetivo: "El Magisterio como función creadora". "La educación del hogar". "La estética es la base de toda la educación". "La educación de la sensibilidad en la niñez y en la juventud". "La educación de la mente". "Práctica de la educación". "Krishnamurti".

Hay otro volumen, también inédito, que contiene conferencias y temas sociológicos; otro sobre Filosofía trascendental; otro más, que titula Apuntes de filosofía del derecho, y el último, concebido por aquella cabeza tan poblada de inquietudes abnegadas, de entrega a la juventud hispanoamericana: Alma continental. Los escombros de un mundo. En esta obra es apostólico, con un sano amor hacia la juventud. Juventud en todos sus pensamientos, conforme pueden leerse los capítulos, entre otros: "Ando buscando juventud" ; Cuál es la juventud que yo busco"; "Otra vez la alondra canta"; "Estoy hablando con los jóvenes"; "Tengo un ideal para los jóvenes"; "La juventud desorientada"; "El hartazgo del libro"; "Llegó ya el Anticristo". Y otros capítulos interesantísimos.

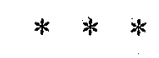

Para la actualidad sangrienta en que se debate el mundo y que comprende a todos los hombres del planeta, Santiago Argüello llenaba una misión humana en la órbita de la pequeña Nicaragua. Un hombre de sus capacidades líricas y de su cultura moderna, tenía forzosamente que inclinarse con simpatía al lado de las democracias, de las izquierdas que anhelan la libertad. Había mucha propaganda totalitaria en América, mucha preparación hábil, subterránea y descarada. Falangistas equivocados, publicidad loca que obraba su efecto en ciertos sectores de la juventud permeable. Santiago Argüello arribaba como una esperanza de catequización. $Y$ su muerte, por eso, constituye un gran dolor no sólo en la literatura sino -y esencialmente - para la vida en la política, en la ciencia de vivir y hacer la vida feliz dentro de la libertad de los hombres.

Santiago Argüello nos emocionaba con su moral poética y con la música de ella misma; nos enardecía su inspiración ; nos convencía del prodigio del vaticjnio que dió desde lo remoto de los tiempos el nombre de vates a los poetas que cantaban todas las cosas de la vida y de la muerte, de lo futuro y lo presente, de lo aproximado y lo misterioso, de lo doloroso y de lo invisible. Llegó el instante de las pro- 
fecias era para nosotros, la adolescencia, la niñez de la época, un leño salvavidas en la tempestad. Y "El águila y la hoja" una clara lección cuando

.. ya lo ois ¡oh guiñapos de la calle vecina!
¡Cobrad ánimo, estultos! ¡No desmayéis, babiecas!
Que si en la tierra un loco viento se arremolina
más alto que las águilas suben las hojas secas.

Y para los que hemos pensado, como José Martí, que el vino nuestro, aunque sea agrio nuestro vino es, cada una de las expresiones de Tierra cálida sacudía una cuerda autóctona y veíamos con ojos de poesía las pedestres cosas que idealizaba el poeta, las humildes cosas que se elevaban al conjuro de su estro, que sufrían la metamorfosis de la taumaturgia trascendental que dora el lodo y pone alas al gusano. Pasa el campesino sentimental cantando tonadas a la novia que todos hemos tenido, como si la picadura fuera sentencia divina, apareada a las otras sentencias del Paraíso. Las mañanitas de mi tierra abren su magia en el cuadro de montañas azules y volcanes ígneos, junto a los lagos tallados en piedra preciosa de una sola pieza. Paisaje. Espíritu. Por algo grabó en los dos brazos únicos y universales del sentimiento este poeta lapidario dos palabras no más, apenas sujetas por el lazo de una letra conjuntiva que las acerca en su inmensidad de antípodas: Ojo y Alma. Ojo y alma hay en la poesía de Santiago Argüello, satisfaciendo los dos conceptos tiranos de lo objetivo y lo subjetivo, impostergables, fríos, absolutos. El hombre que los domina en el ambidextrismo sabio de la exposición de la belleza, ya tiene el secreto de ella misma, ya puede ufanarse de haberla tomado toda entera, obligándola a la completa fidelidad. Poseerá sus carnes y su pensamiento; tendrá la llave en la mano fuerte; dormirá tranquilo en el lecho de los ensueños, sin ninguna preocupación que llegue a despertarlo. Pero...

Pero más lo necesitábamos como Hombre, en estos momentos, Como Pensador situado en la recia y sagrada posición de maestro. Eso es lo que nos preocupa más. Lo otro, la armonía de esa caja de música quebrada por el sino, era valioso también; mas no era tan urgente como lo de maestro. Las arpas suenan desde la infancia inmortal de los pueblos grandes; pero para que fueran divinas, sin yemas de músicos mortales, los dioses las hacían pender de las ramas de los árboles en la floresta. Nosotros no tenemos ni floresta, ni ár- 
boles, ni espiguitas que estiren el cuello en ambición de cielo. El que venía con el morral repleto de semillas para la siembra, no será más que una de tantas contribuciones de abono químico. Aunque su música siga sonando, aunque la armonía de sus versos ponga arreboles en los incomparables telones de la poética.

Ya habrá oportunidad para un análişis amplio. En todos los tiempos, Santiago Argüello será el resumen de las dos condiciones más grandes del individuo: fuerza y belleza. A lo de la poesía airosa juntaba nuestro poeta el fondo firme, de una solidez que casi no se podría concebir en la encajería. Oro y acero era Santiago Argüello en su considerable obra. Oro de las empuñaduras de las dagas toledanas en el acero que jamás ha admitido ángulos.

Sobre todo, como maestro de voluntad es como hoy hace más falta.

\author{
Hernán Robleto, \\ Managua, Nicaragua.
}


